they drink! Heather (1993) has written, "implantation was pioneered by Wilson (1995) in Canada". In fact the initial study was that of Marie in 1955; his work and a variety of French and Italian papers in the 1950s and 1960s are discussed in Jacques' booklet (1970). Marie in 1955 also doubted the activity of implants.

We agree with Shergill and co-workers that, "implantation has a powerful placebo effect", in our view solely placebo, certainly after the first week. It would be interesting to see our biochemical investigations repeated. We still believe, as in 1974, that for disulfiram, "the need exists for development of an alternative form of parenteral administration".

HeATHER, N. (1993) Treatment Options in Addiction. London: Gaskell.

JACgues. D. (1970) Etude de l'utilisation de l'implant de disulfirame dans le traitment de la maladie alcoolique. Monographie No 2. Du Centre International, D'Alcoologie/Toxicomanies: Lausanne (Suisse).

MALCOLM, M. T. \& MADDEN, J. S. (1973) The use of disulfiram implantation in alcoholism. British Journal of Psychiatry. 123, 41-45.

-, - \& Williams, S. E. (1974) Disulfiram implantation critically evaluated. British Journal of Psychiatry. 125. 485-489.

VAN DER LanN (1992) Financial Times, 14 Nov.

M. T. MALCOLM, Clatterbridge Hospital, Wirral L63 4JY, and J. S. MADDEN, West Cheshire Hospital, Chester $\mathrm{CH} 13 \mathrm{ST}$

\section{SSRI prescribing in the elderly: caution required}

Sir: McAskill \& Taylor (Psychiatric Bulletin, January $1997,21,33-35$ ) rightly bring to our attention the potential dangers associated with prescribing antidepressants, particularly SSRIs in the elderly. The syndrome of inappropriate antidiuretic hormone secretion (SIADH) is not uncommon in the elderly (Bouman et al, 1997a) and may lead to serious neurological sequelae. We agree that more careful monitoring of sodium levels are required in these cases, although in our experience this is not yet current practice. As is pointed out in their account, most information on the subject is through individual case reports at present, although we have made a retrospective study of elderly psychiatric in-patients prescribed SSRIs to assess the incidence of SIADH. Preliminary results suggest an incidence of $10 \%$ of SSRI-induced hyponatraemia associated with SIADH. These results need further validation and suggest the need for a larger prospective study to be carried out.

We would also like to draw the authors' attention to a report in press which describes the cross-over effect between one class of antidepressant and another (Bouman et al, 1997b).
In this case hyponatraemia due to SIADH occurred both when sertraline and when lofepramine were prescribed at different times. This would suggest that this phenomenon is not a class effect as previously suggested (Ball \& Hertzberg, 1994).

BALL, C. J. \& HERZBERG, J. L. (1994) Hyponatraemia and selective serotonin inhibitors. International Joumal of Geriatric Psychiatry, 9, 819-822.

Bouman, W. P., Johnson, H. \& PINNER, G. (1997a) Inappropriate antidiuretic hormone secretion and SSRIs. British Journal of Psychiatry, 170, 88-89.

- - Trescol-SerRano, C.. et al (1997b) Recurrent hyponatraemia associated with sertraline and lofepramine. American Journal of Psychiatry. in press.

Gillian PinNer, Walter P. Bouman and Hazel JoHNSON, Department of Health Care of the Elderly, Queens Medical Centre, Nottingham NG7 $2 U H$

Sir: I would like to comment further on the recent drug information quarterly (Psychiatric Bulletin. January 1997, 21, 33-35). A review of spontaneous reports of hyponatraemia and the syndrome of inappropriate anti-diuretic hormone (SIADH) associated with the use of selective serotonin reuptake inhibitors (SSRIs) concluded that the elderly may be at increased risk (Liu et al, 1996). Diuretics are commonly prescribed to the elderly in primary care, and often their usage is inappropriate, for example, to treat gravitational oedema (British National Formulary 31, March 1996. Prescribing in the Elderly). Hyponatraemia is a well recognised adverse effect of thiazide diuretics in the elderly, especially among elderly women (Baglin et al, 1995). Concurrent prescription of SSRIs and a diuretic may therefore increase the risk of hyponatraemia and will create difficulties in identifying the culprit drug, as both will cause an increase in urine osmolality. I suggest caution is exercised in the concurrent prescription of SSRIs and diuretics in the elderly, and that if this combination is used, it is accompanied by regular measurements of serum sodium.

Bagun, A., Boulard, J. C., Hansuk, T., et al (1995) Metabolic adverse reactions to diuretics-Clinical relevance to elderly patients. Drug Safety. 12. 161-167.

Lu, B. A. Mittman, N., Knowles, S. R., et al (1996) Hyponatraemia and the syndrome of inappropriate secretion of anti-diuretic hormone associated with the use of selective serotonin reuptake inhibitors: a review of spontaneous reports. Canadian Medical Association Journal, 155, 519-527.

CATHERINe ANDRewS, Psychiatric Unit, Queen's Medical Centre, Nottingham NG7 $2 U H$ 